REPLY

\section{Platelet noradrenaline uptake is unrelated to renal denervation}

\section{Nicolas Barber-Chamoux and Murray D. Esler}

We read with interest the Perspectives article by Gulati and colleagues (The rise, fall, and possible resurrection of renal denervation. Nat. Rev. Cardiol. 13, 238-244; 2016) ${ }^{1}$. The subsequent correspondence by Shi-Sheng Zhou and Yiming Zhou (Renal denervation for resistant hypertension: the wrong target? Nat. Rev. Cardiol. 13, 388; 2016) ${ }^{2}$ hypothesized that sympathetic nerve biology and noradrenaline plasma kinetics could explain why the current theoretical basis for renal denervation therapy might be flawed. Their argument is based on the importance of platelets in noradrenaline disposition after release of the transmitter from sympathetic nerves in individual organs, and in clearance of noradrenaline from the circulation, concepts which have not been previously described. The authors claim that removal of noradrenaline from plasma, in addition to uptake by platelets, is dependent on excretion by the kidneys.

First, on the matter of noradrenaline plasma clearance, the authors have omitted the important influence of neuronal uptake of noradrenaline from the plasma pool in their Figure $^{2,3}$. Moreover, regarding the importance of renal excretion and platelet uptake, tracer kinetics analyses demonstrated that total noradrenaline plasma clearance is $2-41 / \mathrm{min}$ in humans ${ }^{4}$. This clearance value is equivalent to the calculated sum of clearances in individual organs, indicating that substantial removal of noradrenaline from plasma occurs only in the regional microcirculations of the body. In physiological conditions, how could glomerular filtration, at $70-150 \mathrm{ml} / \mathrm{min}$, match the measured rate of noradrenaline clearance of $2-41 / \mathrm{min}$ ? Impaired renal function could have only a very limited effect on this clearance.

Platelet uptake has been well described, and has been helpful in diagnosing pheochromocytoma ${ }^{5}$ for a reason that contrasts with the authors' hypothesis. When noradrenaline concentration in plasma is subject to variations, platelet concentration is more stable, and is a better representation of the mean release by pheochromocytoma. This smoothing is caused by a slow platelet uptake mechanism with a low affinity process.

In our opinion, two weaknesses should lead to rejection of this platelet hypothesis. First, this 'in and out' flux is too slow to influence transmitter availability and spillover to plasma after release. Noradrenaline spillover to plasma has been shown to be primarily determined by rates of sympathetic nerve firing ${ }^{6}$. Second, even if the noradrenaline concentration is higher in platelets, the platelet pool size is trivial in relation to blood plasma. This imbalance is too important for platelet noradrenaline uptake to contribute substantially to plasma clearance of the transmitter.

In conclusion, at this stage, renal sympathetic denervation faces many challenges, but the novel idea of an underestimated role of platelets in its failure is not well sustained.
Some technical problems have already been described with more consistent data to explain the discrepancy in results from the SYMPLICITY-HTN 3 trial $^{1}$.

There is a Reply to this Correspondence by Zhou, S.-S. \& Zhou, Y. Platelet noradrenaline overload - cause of noradrenaline spillover in hypertension? doi:10.1038/nrcardio.2016.145 (2016).

$$
\begin{aligned}
& \text { Nicolas Barber-Chamoux is at the Baker IDI Heart and } \\
& \text { Diabetes Institute, } 75 \text { Commercial Road, Melbourne, } \\
& \text { Victoria 3004, Australia and Cardiology Department, } \\
& \text { Clermont-Ferrand University Hospital, } 58 \text { Rue } \\
& \text { Montalembert, 63000 Clermont-Ferrand, France. } \\
& \text { Murray D. Esler is at the Baker IDI Heart and Diabetes } \\
& \text { Institute, 75 Commercial Road, Melbourne, Victoria } \\
& \text { 3004, Australia. } \\
& \text { Correspondence to N.B.-C. } \\
& \text { nbarber-chamoux@chu-clermontferrand.fr } \\
& \quad \text { doi:10.1038/nrcardio.2016.144 } \\
& \text { Published online 22 Sep 2016 } \\
& \text { Gulati, R., Raphael, C. E., Negoita, M., Pocock, S. J. } \\
& \text { \& Gersh, B. J. The rise, fall, and possible resurrection } \\
& \text { of renal denervation. Nat. Rev. Cardiol. 13, 238-244 } \\
& \text { (2016). } \\
& \text { Zhou, S.-S. \& Zhou, Y. Renal denervation for resistant } \\
& \text { hypertension: the wrong target? Nat. Rev. Cardiol. 13, } \\
& \text { 388 (2016). } \\
& \text { Eisenhofer, G., Smolich, J. J. \& Esler, M. D. Disposition } \\
& \text { of endogenous adrenaline compared to noradrenaline } \\
& \text { released by cardiac sympathetic nerves in the } \\
& \text { anaesthetized dog. Naunyn Schmiedebergs Arch. } \\
& \text { Pharmacol. 345, 160-171 (1992). } \\
& \text { Esler, M. et al. Overflow of catecholamine } \\
& \text { neurotransmitters to the circulation: source, fate, } \\
& \text { and functions. Physiol. Rev. 70, 963-985 (1990). } \\
& \text { Zweifler, A. J. \& Julius, S. Increased platelet } \\
& \text { catecholamine content in pheochromocytoma: } \\
& \text { a diagnostic test in patients with elevated plasma } \\
& \text { catecholamines. N. Engl. J. Med. 306, 890-894 } \\
& \text { (1982). } \\
& \text { Eisenhofer, G. et al. Cardiac sympathetic nerve } \\
& \text { function in congestive heart failure. Circulation 93, } \\
& \text { 1667-1676 (1996). }
\end{aligned}
$$

\section{Acknowledgements}

N.B.-C. is supported by the Fédération Française de Cardiologie for his fellowship at the Baker IDI Heart and Diabetes Institute, Australia. He received a travel grant from TERUMO. M.D.E. is supported by career fellowships from NHMRC.

\section{Competing interests statement}

M.D.E. has received research funding from Medtronic. He serves on scientific boards of Abbott Pharmaceuticals and Medtronic. N.B.-C. declares no competing interests. 